\title{
Th17 Cytokines and the Gut Mucosal Barrier
}

\author{
Christoph Blaschitz • Manuela Raffatellu
}

Received: 29 December 2009 / Accepted: 7 January 2010 / Published online: 2 February 2010

(C) The Author(s) 2010. This article is published with open access at Springerlink.com

\begin{abstract}
Local immune responses serve to contain infections by pathogens to the gut while preventing pathogen dissemination to systemic sites. Several subsets of $\mathrm{T}$ cells in the gut (T-helper 17 cells, $\gamma \delta \mathrm{T}$ cells, natural killer (NK), and NK-T cells) contribute to the mucosal response to pathogens by secreting a subset of cytokines including interleukin (IL)-17A, IL-17F, IL-22, and IL-26. These cytokines induce the secretion of chemokines and antimicrobial proteins, thereby orchestrating the mucosal barrier against gastrointestinal pathogens. While the mucosal barrier prevents bacterial dissemination from the gut, it also promotes colonization by pathogens that are resistant to some of the inducible antimicrobial responses. In this review, we describe the contribution of Th17 cytokines to the gut mucosal barrier during bacterial infections.
\end{abstract}

Keywords IL-17 · IL-22 · gut inflammation · Th17

\section{Intestinal Pathogens and the Gut Mucosal Barrier}

In normal individuals, the gut mucosa constitutes a barrier against the systemic spread of both pathogenic microorganisms and the resident intestinal microbiota. Once this barrier

C. Blaschitz $\cdot$ M. Raffatellu $(\bowtie)$

Department of Microbiology and Molecular Genetics, University of California Irvine,

Irvine, CA 92697, USA

e-mail:manuelar@uci.edu

C. Blaschitz $\cdot$ M. Raffatellu Institute of Immunology, University of California Irvine, Irvine, CA 92697, USA has been breached, dissemination of microbes from the gut can result in a systemic disease known generally as sepsis. With regards to bacteria, the frequency of bacteremia (bacterial sepsis) is higher in patients with altered mucosal immunity (such as children and the elderly) as well as in patients affected by immunodeficiency, implicating the mucosal barrier as an important line of defense against bacterial dissemination $[1,2]$. Similarly, increased permeability of the mucosal barrier with concomitant bacterial translocation has been reported in Crohn's disease [2].

A portion of the gut mucosal barrier function is orchestrated by the intestinal microbiota that coexist with the host in a mutually beneficial symbiosis [3]. These functions include inducing secretory IgA production and intraepithelial lymphocyte recruitment as well as providing a physical blockade to pathogen colonization [4]. At least one of these mucosal defenses or others to be detailed below must be circumvented or endogenously fail for pathogens or the resident microbiota to disseminate beyond the gut mucosa.

Some intestinal pathogens including nontyphoidal Salmonella (including Salmonella typhimurium), Campylobacter, and Shigella cause inflammatory diarrhea and are characterized by their ability to invade the intestinal mucosa. In stark contrast to these organisms, the closely related pathogens enterohemorrhagic Escherichia coli (EHEC) and enteropathogenic E. coli (EPEC), among others, cause secretory diarrhea and are noninvasive [5]. With regards to the latter group, these strains of $E$. coli belong to the class of organisms known as attaching-effacing (AE) bacteria because they form characteristic $\mathrm{AE}$ lesions as a result of their intimate adhesion with the intestinal mucosa. As both EHEC and EPEC are poorly pathogenic in mice, Citrobacter rodentium, a natural mouse pathogen related to $E$. coli which also causes $\mathrm{AE}$ lesion formation, has been widely used as an experimental model for AE pathogens and will thus be included in this discussion [6]. 


\section{Orchestrating the Gut Mucosal Barrier: an Emerging Role for T Cells}

The host innate immune system is activated by pathogenassociated molecular patterns such as lipopolysaccharide and flagellin [7]. Epithelial cells, macrophages, and dendritic cells play an important role in the initial response to mucosal pathogens. However, there is mounting evidence that direct interaction of pathogens with these cells is not sufficient to generate an effective mucosal response.

Resident $\mathrm{T}$ cells represent a major component of the gut mucosa and are located in between epithelial cells (intraepithelial lymphocytes) and in the lamina propria [8]. It is the intraepithelial lymphocytes that likely contribute to the barrier function and integrity of the intestinal epithelium [9, 10]. Several subsets of $T$ cells $(\alpha \beta, \gamma \delta, N K$, NK-T) are present in the gut mucosa and play an important role in mucosal immunity [11]. Perhaps the most striking evidence of the role $\mathrm{T}$ cells play in mucosal immunity comes from patients infected with the human immunodeficiency virus (HIV). HIV infects CD4+ T cells in the gut as early as a few weeks after infection, resulting in almost complete loss of this cell population [12-14]. Loss of mucosal CD4+ T-helper cells consequently results in a loss of function of both $\mathrm{B}$ cells and CD8 $+\mathrm{T}$ cells [15]. In HIV patients, CD4 $+\mathrm{T}$ cell depletion results in increased susceptibility to bacteremia caused by intestinal pathogens (mostly Salmonella, but also Shigella and Campylobacter) [16-18]. This indicates that $\mathrm{CD} 4+\mathrm{T}$ cells are essential for the mucosal barrier against pathogens that normally cause inflammatory diarrhea.

In the mouse model, depletion of either CD4+ or CD8+ T cell subsets results in increased translocation of $E$. coli to the mesenteric lymph nodes [19]. While mice do not develop inflammatory diarrhea when infected with S. typhimurium, streptomycin-pretreated mice infected with $S$. typhimurium develop an acute inflammatory response in the cecum [20]. In this model, CD3+ (T cell) depletion results in dramatic reduction of the gross pathology, neutrophil influx, and expression of pro-inflammatory cytokines and chemokines [21]. Similarly, CD3 + depletion or the absence of $\alpha \beta$ T cells both result in reduced clearance of $C$. rodentium infection in mice [22, 23]. Overall, both clinical and experimental evidence reveal that mucosal $\mathrm{T}$ cells play an important role in containing commensals and pathogens to the gut.

\section{Th17 Cells Orchestrate the Mucosal Response to Gut Pathogens}

Several studies have suggested that a new subset of T cells, termed T-helper 17 (Th17) cells, orchestrate the mucosal defense against pathogens. Th17 cells constitute a distinct lineage from Th1 and Th2 cells and are characterized by the production of a subset of cytokines: IL-17A, IL-17F, IL-22, and IL-26 [24]. Th17 cell differentiation is directed by the transcription factor ROR $\gamma \mathrm{t}$, which is specific for the Th17 lineage [25]. The pro-inflammatory cytokines interleukin (IL)- 6 and TGF- $\beta$ appear to drive Th17 differentiation, at least in the mouse model [26], while the cytokine IL-23 appears to be indispensable for the protective effect of the Th17 response against mucosal pathogens like C. rodentium, Klebsiella pneumoniae, and S. typhimurium [27-29].

Another layer of complexity to the mucosal response to pathogens is that Th17 cytokines can be secreted by other cell types. IL-17 is released by $\gamma \delta \mathrm{T}$ cells in response to IL-23 stimulation [30, 31]. NK and NK-T cells can produce IL-17 and IL-22 [32, 33]. Antigen-presenting cells such as dendritic cells can secrete IL-22 in response to bacterial infection [34]. The cytokines IL-17A, IL-17F, and IL-22 are expressed in the mucosa in response to several bacterial and fungal pathogens; examples include $K$. pneumoniae infection in the lung, $C$. rodentium and $S$. typhimurium infection in the gut, Candida albicans infection of the oral cavity, and many others (reviewed in [35]).

Adaptive T cells (Th17 cells), innate-like T cells $(\gamma \delta \mathrm{T}$ cells), or both can contribute to the host mucosal immune response. The contribution of Th17 cells during C. rodentium infection is evident during the second week post-infection [27]. In contrast, IL-17 expression occurs quite early during $S$. typhimurium infection, ranging from $5 \mathrm{~h}$ post-inoculation of rhesus macaque ileal loops to $48 \mathrm{~h}$ post-oral infection in mice $[29,36]$. The vast majority of gut $\mathrm{T}$ cells in the aforementioned rhesus macaque study were either CD4+ or CD8+ with $\gamma \delta \mathrm{T}$ cells comprising less than $1 \%$ of the total gut $\mathrm{T}$ cell population; this result suggests that $\gamma \delta \mathrm{T}$ cells are not a major source of IL-17 at $5 \mathrm{~h}$ post-S. typhimurium infection in adult rhesus macaques. In line with this observation, IL-17 production in response to $S$. typhimurium infection was dramatically decreased in macaques previously infected with the simian immunodeficiency virus which causes a selective loss of CD4+ $\mathrm{T}$ cells in the gut (comprising both Th1 and Th17 cells) [36]. In the mouse model, $\gamma \delta \mathrm{T}$ cells contributed to the IL-17 produced at day 2 post-infection, but they were not the sole source [29]. It thus appears that early activation of both adaptive and innate-like $\mathrm{T}$ cells can lead to expression of IL-17 and IL-22. As these T cells express the IL-23 receptor, expression of IL-23 by dendritic cells comprises a common trigger or potentiating factor for early $\mathrm{T}$ cell activation prior to the development of adaptive immunity.

\section{Th17 Development in the Gut Depends on Microbiota Composition}

The gut microbiota is primarily composed of bacteria belonging to the phyla Bacteroidetes and Firmicutes [37, 
38]. As demonstrated in gnotobiotic (lacking microbiota) mouse studies, development of gut immunity is strongly influenced by the intestinal microbiota. It was recently shown that some bacteria of the genus Clostridia (phylum Firmicutes), termed segmented filamentous bacteria (SFB), are essential to the development of Th17 cells in the mouse gut [39-42]. One host factor that influences the composition of the gut microbiota, including colonization by SFB, is the expression of antimicrobial peptides such as defensins [42]. Expression of a human specific alpha defensin (DEFA5) in the mouse dramatically changes the microbiota composition, including the loss of SFB [42]. Concomitant with these changes in the microbiota, fewer IL-17 producing $\mathrm{T}$ cells were isolated from the lamina propria. In contrast, mice colonized with SFB had an increased expression of genes associated with inflammation and antimicrobial defense and were subsequently more resistant to infection with $C$. rodentium [41]. These recent studies demonstrate that specific members of the gut microbiota can shape aspects of the mucosal barrier.

\section{Th17 Cytokines Control Pathogen Dissemination from the Mucosa}

The role IL-17 and IL-22 play during mucosal infections has become apparent following several studies that employed mice lacking these cytokines (IL-17A, IL-17F, IL-22), their receptors (IL-17Ra, IL-17Rc), or upstream cytokines responsible for their induction (IL-23 p19 deficient mice). During colonic infection with $C$. rodentium, IL-17A, IL-17F, and IL-22 appear to play a role in controlling the severity of gut pathology [34, 43]. In rhesus macaques, depletion of Th17 cells by SIV results in alteration of the mucosal barrier and increased dissemination of $S$. typhimurium to the mesenteric lymph nodes. Moreover, IL-17Ra ${ }^{-/-}$mice have increased translocation of $S$. typhimurium to the mesenteric lymph nodes and spleen [36]. Ileitis caused by Toxoplasma gondii infection is dependent on IL-23 stimulated IL-22 production by CD4+ $\mathrm{T}$ cells in the small intestinal lamina propria [44]. As illustrated in these and other studies, IL-17 and IL-22 upregulation appear to comprise a stereotypic response to infection with mucosal pathogens.

Receptors of IL-17A and IL-17F (IL-17Ra and IL-17Rc) are expressed in several cell types, while receptors for IL-22 and IL-26 are expressed solely by epithelial cells [45-48]. Little is known about the role of IL-26 because this cytokine is not present in the mouse genome. In vitro stimulation of intestinal epithelial cells with IL-17, IL-22, or IL-26 induces changes in gene expression, including upregulation of chemokines (CXCL-8, CCL20) and antimicrobial responses (iNos, lipocalin-2) [49-52]. IL-17 also contributes to tight junction formation and increased trans-epithelial resistance in polarized intestinal epithelial cells [53]. Both IL-17 and IL22 stimulate granulopoiesis by inducing expression of the granulocyte colony stimulating factor G-CSF [54-58]. Induction of G-CSF and CXC chemokine expression contribute to neutrophil accumulation and function in the mucosa in response to infection [59, 60]. Th17 cytokines thus contribute to the mucosal barrier by several mechanisms which, upon activation, result in a mucosal immune response geared towards eliminating pathogens.

The mucosal response in patients with inflammatory diarrhea is characterized by a massive neutrophil infiltrate in the intestinal mucosa. Clinical evidence suggests that neutrophils are important in containing diarrheal pathogens to the gut and preventing their systemic spread. In patients affected by primary neutrophil immunodeficiency (i.e., chronic granulomatous disease), $S$. typhimurium often disseminates from the gut, resulting in bacteremia [61, 62]. HIV infection also results in a secondary neutrophil immunodeficiency [63, 64] which is likely a contributing factor to the susceptibility of HIV patients to bacteremia [65]. In the mouse model of inflammatory diarrhea, Th17 deficiency results in reduced neutrophil recruitment to the mucosa during infection with $S$. typhimurium [36]. Thus, a defect in neutrophil recruitment may explain why S. typhimurium dissemination increases in the absence of IL-17 signaling.

One of the mucosal responses induced during $C$. rodentium colonic infection is the secretion of antimicrobial C-type lectins of the RegIII family, including Reg3 $\gamma$ and Reg3 $\beta$ [34]. Induction of Reg3 $\gamma$ is dependent on IL-22 and is important in controlling intestinal infection with $C$. rodentium or vancomycin-resistant enterococci $[34,66]$. $\beta$-defensin 1,3 , and 4 are also induced during $C$. rodentium infection in the gut by IL-17A and IL-17F [43], however the role these antimicrobial peptides play in this model is not yet known.

\section{Gut Inflammation Promotes Pathogen Colonization}

Intestinal pathogens replicate in the gut and reach high numbers in the stool in order to achieve transmission via the fecal-oral route. Replication in the gut requires adaptation to harsh conditions including the presence of bile salts, mucus, and the resident microbiota competing for nutrients and binding sites along the intestinal epithelium. Several recent studies suggest that pathogens have an advantage over the resident microbiota in colonizing the gut as both $C$. rodentium and $S$. typhimurium infections lead to overgrowth of the pathogen with concomitant growth suppression of the resident microbiota [67-70]. However, such suppression occurs only in the presence of an inflammatory response, so in the absence of inflammation, the microbiota constitute a barrier against $S$. typhimurium colonization $[67,68]$. While 
the mucosal response is thus effective in keeping pathogens confined to the gut mucosa, it has the unfortunate side effect of promoting pathogen overgrowth in the intestinal lumen.

The mechanisms by which the inflammatory response promotes pathogen growth are not completely understood. One hypothesis is that pathogens thrive in the inflamed gut because they have adapted to access nutrients during inflammation to a higher degree than the resident microbiota. One potential nutrient source during intestinal inflammation may be represented by mucins, which are upregulated by IL17 and IL-22 stimulation of intestinal epithelial cells [49]. The ability of S. typhimurium to swim in the direction of nutrients increases the fitness of the organism in the inflamed intestine, but not in the normal gut [71]. Induction of the mucin MUC1 was observed in the distal colon of patients infected with Salmonella saintpaul and Campylobacter jejuni [72], suggesting that pathogen colonization of the mucus layer may be relevant for the pathogenesis of inflammatory diarrhea in humans. Fitting in with this idea, it was recently demonstrated that mucin can be degraded by a serine protease autotransporter (the Pic mucinase) expressed by enteroaggregative E. coli (EAEC) and Shigella flexneri $[73,74]$. In a mouse model of infection, the Pic mucinase enhances EAEC colonization and growth in the presence of mucins, thereby enhancing fitness of this pathogen [74].

While the acquisition of carbon, nitrogen, and oxygen atoms are essential for the growth of any organism, so too is the acquisition metal ions. One host strategy to fight infections is to reduce the accessibility of metal ions. The most studied metal ion with regards to bacterial infection is iron, an essential micronutrient. Under normal conditions, iron is largely bound to serum transferrin. In the inflamed gut, lactoferrin secreted by neutrophils functions as another iron-binding molecule, exhibiting greater iron affinity at low $\mathrm{Ph}$ than transferrin [75]. To overcome these host defense mechanisms, bacteria secrete iron chelators known as siderophores which have a higher affinity for iron than either transferrin or lactoferrin [76, 77]. Once bound to iron, siderophores are internalized by specialized bacterial transport systems, thereby providing an iron source during iron starvation.

The siderophore enterochelin (produced by most members of Enterobacteriaceae), is a target of the host antimicrobial protein lipocalin-2 [78]. Lipocalin-2 binds to iron-laden enterochelin and prevents its uptake by bacteria, thereby inhibiting growth of susceptible strains [78, 79]. Both in vitro and in vivo, lipocalin-2 expression and secretion is dependent on stimulation of epithelial cells with IL-17 and IL-22 [49, 58]. Thus, lipocalin-2 expression is increased in mucosal surfaces, including the gut, during the course of mucosal infections. As an adaptation to this host defense, pathogens such as $S$. typhimurium, pathogenic E. coli, and some strains of $K$. pneumoniae have developed resistance to lipocalin-2 by encoding for at least one additional siderophore, termed salmochelin [80-83]. Salmochelin is a glycosylated form of enterochelin that is not bound by lipocalin-2, thus its expression restores the ability of bacterial pathogens to acquire iron [49, 84-86].

Iron acquisition through salmochelin promotes $S$. typhimurium colonization of the inflamed gut, but not of the normal gut or in the absence of lipocalin-2 [49]. Thus, the capacity to acquire iron during intestinal inflammation is an important virulence trait for survival in the inflamed gut. Other mucosal pathogens have additional siderophores (yersiniabactin, aerobactin) which also provide an advantage for colonization of mucosal surfaces, although their role in iron acquisition in the inflamed gut remains to be determined [87-89]. Lipocalin-2 is also induced by pathogens at other mucosal surfaces including Streptococcus pneumoniae and Haemophilus influenzae in the nasal mucosa, Helicobacter pylori in the stomach, and C. albicans in the oral cavity [90-92]. These pathogens are not susceptible to lipocalin-2 mediated iron withholding because they do not acquire iron through enterochelin. Although its role in these infection models has yet to be established, it is plausible that lipocalin-2

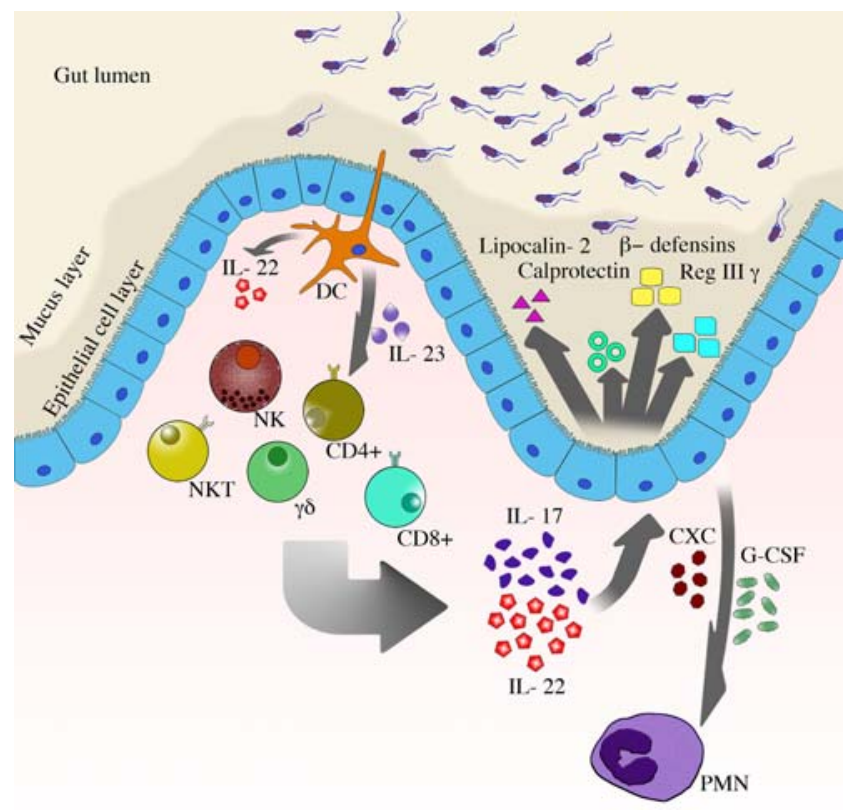

Fig. 1 Th17 cytokines and the gut mucosal barrier. Dendritic cells activated by pathogens secrete several cytokines including IL-22 and IL-23. IL-23 stimulates several subsets of T cells (Th17 cells, $\gamma \delta \mathrm{T}$ cells, NK, and NK-T cells) to secrete IL-17 and IL-22. T cells promote amplification of the host response by stimulating the intestinal epithelium to secrete CXC chemokines (neutrophil chemoattractants) and antimicrobial peptides (lipocalin-2, calprotectin, Reg $3 \gamma$, and $\beta$ defensins). While the Th17 response prevents bacterial dissemination from the gut, it also promotes colonization of the mucosa by pathogens that are resistant to some of the induced antimicrobial responses. The ability to acquire nutrients and associate with the expanded mucous layer during inflammation promotes colonization of pathogenic microbes 
production may be exploited by these pathogens to promote their colonization by suppressing the growth of competitors.

Other metal ions such as zinc and manganese are also essential micronutrients for bacteria. The antimicrobial peptide calprotectin, which is present in neutrophil granules, chelates zinc, and manganese, is involved in host defense against bacterial infections [93]. Expression of the S100A8 and S100A9 subunits of calprotectin is induced in the mucosa in response to IL-17 and IL-22 stimulation [34, 94]. The role that this and other antimicrobial peptides play in host defense to pathogens remains to be established.

\section{Conclusions}

The function of the cytokines IL-17, IL-22, and IL-23 in response to gut pathogens is summarized in the model proposed in Fig. 1. Dendritic cells activated by pathogens secrete cytokines including IL-22 and IL-23 [34, 95]. Several innate-like and adaptive $\mathrm{T}$ cells harbor the IL-23 receptor and are activated by this cytokine to release IL-17 and IL-22 [11]. These cytokines stimulate epithelial cells to express CXC chemokines resulting in neutrophil recruitment to the site of infection. Neutrophils constitute part of the mucosal barrier against inflammatory diarrheal pathogens by containing these infections to mucosal sites and preventing bacteremia [96].

IL-17 and IL-22 also induce the expression and secretion of antimicrobial peptides including lipocalin-2, Reg $3 \gamma, \beta-$ defensins, and calprotectin $[34,43,49,58]$. Some of these antimicrobial peptides may control dissemination from the mucosa, as in the case of $\operatorname{Reg} 3 \gamma$ during $C$. rodentium infection [34], while others such as lipocalin-2 suppress the growth of commensal microbiota and consequently promote the growth of resistant pathogens [49]. Pathogens which have adapted to this hostile environment have acquired a range of virulence factors that provide access to nutrients in the inflamed gut, including glycoproteins in the mucus layer and metal ions.

Pathogens have thus evolved to take advantage of various aspects of the mucosal response to gain an edge over the resident microbiota in colonizing the inflamed gut. Even though the enhancement of pathogen colonization is a "side effect" of IL-17 and IL-22 mediated responses, resolution of diarrhea typically occurs within a few days of its onset. In contrast, defects in Th17-mediated responses like those observed in HIV patients result in increased dissemination of both pathogens and the microbiota, culminating in bacteremia with a high mortality rate [97, 98]. So while Th17 responses appear to be detrimental by promoting pathogen colonization of the mucosa, in the end it is the resulting decrease in bacterial dissemination from the mucosa that protects the host.
Acknowledgments Work in the laboratory of MR is supported by Public Health Service Grant AI083619 and the IDSA ERF/NIFID Astellas Young Investigator Award.

Open Access This article is distributed under the terms of the Creative Commons Attribution Noncommercial License which permits any noncommercial use, distribution, and reproduction in any medium, provided the original author(s) and source are credited.

\section{References}

1. Bearman GM, Wenzel RP. Bacteremias: a leading cause of death. Arch Med Res. 2005;36:646-59.

2. McBean M, Rajamani S. Increasing rates of hospitalization due to septicemia in the US elderly population, 1986-1997. J Infect Dis. 2001;183:596-603.

3. Duerkop BA, Vaishnava S, Hooper LV. Immune responses to the microbiota at the intestinal mucosal surface. Immunity. 2009;31:36876.

4. Umesaki Y, Setoyama H, Matsumoto S, Imaoka A, Itoh K. Differential roles of segmented filamentous bacteria and clostridia in development of the intestinal immune system. Infect Immun. 1999;67:3504-11.

5. Aranda-Michel J, Giannella RA. Acute diarrhea: a practical review. Am J Med. 1999;106:670-6.

6. Mundy R, MacDonald TT, Dougan G, Frankel G, Wiles S. Citrobacter rodentium of mice and man. Cell Microbiol. 2005;7:1697-706.

7. Mogensen TH. Pathogen recognition and inflammatory signaling in innate immune defenses. Clin Microbiol Rev 22:240-73, Table of Contents 2009.

8. van Wijk F, Cheroutre H. Intestinal T cells: facing the mucosal immune dilemma with synergy and diversity. Semin Immunol. 2009;21:130-8.

9. Inagaki-Ohara $\mathrm{K}$, Dewi $\mathrm{FN}$, Hisaeda $\mathrm{H}$, Smith $\mathrm{AL}$, Jimi $\mathrm{F}$, Miyahira M, et al. Intestinal intraepithelial lymphocytes sustain the epithelial barrier function against Eimeria vermiformis infection. Infect Immun. 2006;74:5292-301.

10. Klein JR. T-cell activation in the curious world of the intestinal intraepithelial lymphocyte. Immunol Res. 2004;30:327-37.

11. Agace WW. T-cell recruitment to the intestinal mucosa. Trends Immunol. 2008;29:514-22.

12. Zeitz M, Ullrich R, Schneider T, Kewenig S, Hohloch K, Riecken EO. HIV/SIV enteropathy. Ann N Y Acad Sci. 1998;859:139-48.

13. Guadalupe M, Reay E, Sankaran S, Prindiville T, Flamm J, McNeil A, et al. Severe CD4+ T-cell depletion in gut lymphoid tissue during primary human immunodeficiency virus type 1 infection and substantial delay in restoration following highly active antiretroviral therapy. J Virol. 2003;77:11708-17.

14. Smit-McBride Z, Mattapallil JJ, McChesney M, Ferrick D, Dandekar S. Gastrointestinal T lymphocytes retain high potential for cytokine responses but have severe CD4(+) T-cell depletion at all stages of simian immunodeficiency virus infection compared to peripheral lymphocytes. J Virol. 1998;72:6646-56.

15. Gamberg J, Barrett L, Bowmer MI, Howley C, Grant M. Factors related to loss of HIV-specific cytotoxic T lymphocyte activity. AIDS. 2004;18:597-604.

16. Glaser JB, Morton-Kute L, Berger SR, Weber J, Siegal FP, Lopez $\mathrm{C}$, et al. Recurrent Salmonella typhimurium bacteremia associated with the acquired immunodeficiency syndrome. Ann Intern Med. 1985;102:189-93.

17. Gordon MA. Salmonella infections in immunocompromised adults. J Infect. 2008;56:413-22.

18. Tee W, Mijch A. Campylobacter jejuni bacteremia in human immunodeficiency virus (HIV)-infected and non-HIV-infected 
patients: comparison of clinical features and review. Clin Infect Dis. 1998;26:91-6.

19. Gautreaux MD, Deitch EA, Berg RD. T lymphocytes in host defense against bacterial translocation from the gastrointestinal tract. Infect Immun. 1994;62:2874-84.

20. Barthel M, Hapfelmeier S, Quintanilla-Martinez L, Kremer M, Rohde M, Hogardt M, et al. Pretreatment of mice with streptomycin provides a Salmonella enterica serovar Typhimurium colitis model that allows analysis of both pathogen and host. Infect Immun. 2003;71:2839-58.

21. Godinez I, Haneda T, Raffatellu M, George MD, Paixao TA, Rolan HG, et al. T cells help to amplify inflammatory responses induced by Salmonella enterica serotype Typhimurium in the intestinal mucosa. Infect Immun. 2008;76:2008-17.

22. Bry L, Brenner MB. Critical role of T cell-dependent serum antibody, but not the gut-associated lymphoid tissue, for surviving acute mucosal infection with Citrobacter rodentium, an attaching and effacing pathogen. J Immunol. 2004;172:433-41.

23. Simmons CP, Clare S, Ghaem-Maghami M, Uren TK, Rankin J, Huett A, et al. Central role for B lymphocytes and CD4+ T cells in immunity to infection by the attaching and effacing pathogen Citrobacter rodentium. Infect Immun. 2003;71:5077-86.

24. Wilson NJ, Boniface K, Chan JR, McKenzie BS, Blumenschein WM, Mattson JD, et al. Development, cytokine profile and function of human interleukin 17-producing helper T cells. Nat Immunol. 2007;8:950-7.

25. Ivanov II, McKenzie BS, Zhou L, Tadokoro CE, Lepelley A, Lafaille JJ, et al. The orphan nuclear receptor RORgammat directs the differentiation program of proinflammatory IL-17+ T helper cells. Cell. 2006;126:1121-33.

26. Stockinger B, Veldhoen M. Differentiation and function of Th17 T cells. Curr Opin Immunol. 2007;19:281-6.

27. Mangan PR, Harrington LE, O'Quinn DB, Helms WS, Bullard DC, Elson CO, et al. Transforming growth factor-beta induces development of the $\mathrm{T}(\mathrm{H}) 17$ lineage. Nature. 2006;441:231-4.

28. Happel KI, Dubin PJ, Zheng M, Ghilardi N, Lockhart C, Quinton LJ, et al. Divergent roles of IL-23 and IL-12 in host defense against Klebsiella pneumoniae. J Exp Med. 2005;202:761-9.

29. Godinez I, Raffatellu M, Chu H, Paixao TA, Haneda T, Santos $\mathrm{RL}$, et al. Interleukin-23 orchestrates mucosal responses to Salmonella enterica serotype Typhimurium in the intestine. Infect Immun. 2009;77:387-98.

30. Roark CL, Simonian PL, Fontenot AP, Born WK, O'Brien RL. gammadelta T cells: an important source of IL-17. Curr Opin Immunol. 2008;20:353-7.

31. Martin B, Hirota K, Cua DJ, Stockinger B, Veldhoen M. Interleukin-17-producing gammadelta $\mathrm{T}$ cells selectively expand in response to pathogen products and environmental signals. Immunity. 2009;31:321-30.

32. Colonna M. Interleukin-22-producing natural killer cells and lymphoid tissue inducer-like cells in mucosal immunity. Immunity. 2009;31:15-23.

33. Takatori H, Kanno Y, Watford WT, Tato CM, Weiss G, Ivanov II, et al. Lymphoid tissue inducer-like cells are an innate source of IL-17 and IL-22. J Exp Med. 2009;206:35-41.

34. Zheng Y, Valdez PA, Danilenko DM, Hu Y, Sa SM, Gong Q, et al. Interleukin-22 mediates early host defense against attaching and effacing bacterial pathogens. Nat Med. 2008;14:282-9.

35. Dubin PJ, Kolls JK. Th17 cytokines and mucosal immunity. Immunol Rev. 2008;226:160-71.

36. Raffatellu M, Santos RL, Verhoeven DE, George MD, Wilson RP, Winter SE, et al. Simian immunodeficiency virus-induced mucosal interleukin-17 deficiency promotes Salmonella dissemination from the gut. Nat Med. 2008;14:421-8.
37. Hooper LV, Gordon JI. Commensal host-bacterial relationships in the gut. Science. 2001;292:1115-8.

38. Neish AS. Microbes in gastrointestinal health and disease. Gastroenterology. 2009;136:65-80.

39. Ivanov II, Frutos Rde L, Manel N, Yoshinaga K, Rifkin DB, Sartor RB, et al. Specific microbiota direct the differentiation of IL-17-producing T-helper cells in the mucosa of the small intestine. Cell Host Microbe. 2008;4:337-49.

40. Gaboriau-Routhiau V, Rakotobe S, Lecuyer E, Mulder I, Lan A, Bridonneau $\mathrm{C}$, et al. The key role of segmented filamentous bacteria in the coordinated maturation of gut helper $\mathrm{T}$ cell responses. Immunity. 2009;31:677-89.

41. Ivanov II, Atarashi K, Manel N, Brodie EL, Shima T, Karaoz U, et al. Induction of intestinal Th17 cells by segmented filamentous bacteria. Cell. 2009;139:485-98.

42. Salzman NH, Hung K, Haribhai D, Chu H, Karlsson-Sjoberg J, Amir E, Teggatz P, Barman M, Hayward M, Eastwood D, Stoel M, Zhou Y, Sodergren E, Weinstock GM, Bevins CL, Williams CB, Bos NA. Enteric defensins are essential regulators of intestinal microbial ecology. Nat Immunol 11:76-82

43. Ishigame H, Kakuta S, Nagai T, Kadoki M, Nambu A, Komiyama Y, et al. Differential roles of interleukin-17A and -17F in host defense against mucoepithelial bacterial infection and allergic responses. Immunity. 2009;30:108-19.

44. Munoz M, Heimesaat MM, Danker K, Struck D, Lohmann U, Plickert R, et al. Interleukin (IL)-23 mediates Toxoplasma gondiiinduced immunopathology in the gut via matrixmetalloproteinase-2 and IL-22 but independent of IL-17. J Exp Med. 2009;206:3047-59.

45. Gaffen SL. Structure and signalling in the IL-17 receptor family. Nat Rev Immunol. 2009;228:199-211.

46. Xie MH, Aggarwal S, Ho WH, Foster J, Zhang Z, Stinson J, et al. Interleukin (IL)-22, a novel human cytokine that signals through the interferon receptor-related proteins CRF2-4 and IL-22R. J Biol Chem. 2000;275:31335-9.

47. Wolk K, Kunz S, Witte E, Friedrich M, Asadullah K, Sabat R. IL-22 increases the innate immunity of tissues. Immunity. 2004;21:241-54.

48. Sheikh F, Baurin VV, Lewis-Antes A, Shah NK, Smirnov SV, Anantha S, et al. Cutting edge: IL-26 signals through a novel receptor complex composed of IL-20 receptor 1 and IL-10 receptor 2. J Immunol. 2004;172:2006-10.

49. Raffatellu M, George MD, Akiyama Y, Hornsby MJ, Nuccio SP, Paixao TA, et al. Lipocalin-2 resistance confers an advantage to Salmonella enterica serotype Typhimurium for growth and survival in the inflamed intestine. Cell Host Microbe. 2009;5:476-86.

50. Ziesche E, Bachmann M, Kleinert H, Pfeilschifter J, Muhl H. The interleukin-22/STAT3 pathway potentiates expression of inducible nitric-oxide synthase in human colon carcinoma cells. J Biol Chem. 2007;282:16006-15.

51. Dambacher J, Beigel F, Zitzmann K, De Toni EN, Goke B, Diepolder HM, et al. The role of the novel Th17 cytokine IL-26 in intestinal inflammation. Gut. 2009;58:1207-17.

52. Brand S, Beigel F, Olszak T, Zitzmann K, Eichhorst ST, Otte JM, et al. IL-22 is increased in active Crohn's disease and promotes proinflammatory gene expression and intestinal epithelial cell migration. Am J Physiol: Gasterointest Liver Physiol. 2006;290:G827-38.

53. Kinugasa T, Sakaguchi T, Gu X, Reinecker HC. Claudins regulate the intestinal barrier in response to immune mediators. Gastroenterology. 2000;118:1001-11.

54. McAllister F, Henry A, Kreindler JL, Dubin PJ, Ulrich L, Steele C, et al. Role of IL-17A, IL-17F, and the IL-17 receptor in regulating growth-related oncogene-alpha and granulocyte colony-stimulating factor in bronchial epithelium: implications for airway inflammation in cystic fibrosis. J Immunol. 2005; 175:404-12. 
55. Ye P, Rodriguez FH, Kanaly S, Stocking KL, Schurr J, Schwarzenberger $\mathrm{P}$, et al. Requirement of interleukin 17 receptor signaling for lung CXC chemokine and granulocyte colonystimulating factor expression, neutrophil recruitment, and host defense. J Exp Med. 2001;194:519-27.

56. Cai XY, Gommoll Jr CP, Justice L, Narula SK, Fine JS. Regulation of granulocyte colony-stimulating factor gene expression by interleukin-17. Immunol Lett. 1998;62:51-8.

57. Numasaki M, Takahashi H, Tomioka Y, Sasaki H. Regulatory roles of IL-17 and IL-17F in G-CSF production by lung microvascular endothelial cells stimulated with IL-1beta and/or TNF-alpha. Immunol Lett. 2004;95:97-104.

58. Aujla SJ, Chan YR, Zheng M, Fei M, Askew DJ, Pociask DA, et al. IL-22 mediates mucosal host defense against Gram-negative bacterial pneumonia. Nat Med. 2008;14:275-81.

59. Laan M, Cui ZH, Hoshino H, Lotvall J, Sjostrand M, Gruenert DC, et al. Neutrophil recruitment by human IL-17 via C-X-C chemokine release in the airways. J Immunol. 1999;162:2347-52.

60. Roilides E, Walsh TJ, Pizzo PA, Rubin M. Granulocyte colonystimulating factor enhances the phagocytic and bactericidal activity of normal and defective human neutrophils. J Infect Dis. 1991;163:579-83.

61. Mouy R, Fischer A, Vilmer E, Seger R, Griscelli C. Incidence, severity, and prevention of infections in chronic granulomatous disease. J Pediatr. 1989;114:555-60.

62. Winkelstein JA, Marino MC, Johnston Jr RB, Boyle J, Curnutte J, Gallin JI, et al. Chronic granulomatous disease. Report on a national registry of 368 patients. Medicine (Baltimore). 2000;79:155-69.

63. Pitrak DL, Bak PM, DeMarais P, Novak RM, Andersen BR. Depressed neutrophil superoxide production in human immunodeficiency virus infection. J Infect Dis. 1993;167:1406-10.

64. Kuritzkes DR. Neutropenia, neutrophil dysfunction, and bacterial infection in patients with human immunodeficiency virus disease: the role of granulocyte colony-stimulating factor. Clin Infect Dis. 2000;30:256-60.

65. Tumbarello M, Tacconelli E, Caponera S, Cauda R, Ortona L. The impact of bacteraemia on HIV infection. Nine years experience in a large Italian university hospital. J Infect. 1995;31:123-31.

66. Brandl K, Plitas G, Mihu CN, Ubeda C, Jia T, Fleisher M, et al. Vancomycin-resistant enterococci exploit antibiotic-induced innate immune deficits. Nature. 2008;455:804-7.

67. Lawley TD, Bouley DM, Hoy YE, Gerke C, Relman DA, Monack DM. Host transmission of Salmonella enterica serovar Typhimurium is controlled by virulence factors and indigenous intestinal microbiota. Infect Immun. 2008;76:403-16.

68. Stecher B, Robbiani R, Walker AW, Westendorf AM, Barthel M, Kremer M, et al. Salmonella enterica serovar typhimurium exploits inflammation to compete with the intestinal microbiota. PLoS Biol. 2007;5:2177-89.

69. Lupp C, Robertson ML, Wickham ME, Sekirov I, Champion OL, Gaynor EC, et al. Host-mediated inflammation disrupts the intestinal microbiota and promotes the overgrowth of Enterobacteriaceae. Cell Host Microbe. 2007;2:204.

70. Barman M, Unold D, Shifley K, Amir E, Hung K, Bos N, et al. Enteric salmonellosis disrupts the microbial ecology of the murine gastrointestinal tract. Infect Immun. 2008;76:907-15.

71. Stecher B, Barthel M, Schlumberger MC, Haberli L, Rabsch W, Kremer M, et al. Motility allows S. Typhimurium to benefit from the mucosal defence. Cell Microbiol. 2008;10:1166-80.

72. Linden SK, Florin TH, McGuckin MA. Mucin dynamics in intestinal bacterial infection. PLoS ONE. 2008;3:e3952.

73. Henderson IR, Czeczulin J, Eslava C, Noriega F, Nataro JP. Characterization of pic, a secreted protease of Shigella flexneri and enteroaggregative Escherichia coli. Infect Immun. 1999;67:5587-96.
74. Harrington SM, Sheikh J, Henderson IR, Ruiz-Perez F, Cohen PS, Nataro JP. The Pic protease of enteroaggregative Escherichia coli promotes intestinal colonization and growth in the presence of mucin. Infect Immun. 2009;77:2465-73.

75. Ong ST, Ho JZ, Ho B, Ding JL. Iron-withholding strategy in innate immunity. Immunobiology. 2006;211:295-314.

76. Ratledge C. Iron metabolism and infection. Food Nutr Bull. 2007;28:S515-23.

77. Braun V, Hantke K, Koster W. Bacterial iron transport: mechanisms, genetics, and regulation. Met Ions Biol Syst. 1998;35:67-145.

78. Flo TH, Smith KD, Sato S, Rodriguez DJ, Holmes MA, Strong RK, et al. Lipocalin 2 mediates an innate immune response to bacterial infection by sequestrating iron. Nature. 2004;432:91721.

79. Berger T, Togawa A, Duncan GS, Elia AJ, You-Ten A, Wakeham A, et al. Lipocalin 2-deficient mice exhibit increased sensitivity to Escherichia coli infection but not to ischemia-reperfusion injury. Proc Natl Acad Sci U S A. 2006;103:1834-9.

80. Baumler AJ, Tsolis RM, van der Velden AW, Stojiljkovic I, Anic $\mathrm{S}$, Heffron F. Identification of a new iron regulated locus of Salmonella typhi. Gene. 1996;183:207-13.

81. Fischbach MA, Lin H, Zhou L, Yu Y, Abergel RJ, Liu DR, et al. The pathogen-associated iroA gene cluster mediates bacterial evasion of lipocalin 2. Proc Natl Acad Sci U S A. 2006;103:16502-7.

82. Bister B, Bischoff D, Nicholson GJ, Valdebenito M, Schneider K, Winkelmann G, et al. The structure of salmochelins: C-glucosylated enterobactins of Salmonella enterica. Biometals. 2004;17:47181.

83. Hantke K, Nicholson G, Rabsch W, Winkelmann G. Salmochelins, siderophores of Salmonella enterica and uropathogenic Escherichia coli strains, are recognized by the outer membrane receptor IroN. Proc Natl Acad Sci U S A. 2003;100:3677-82.

84. Fischbach MA, Lin H, Liu DR, Walsh CT. How pathogenic bacteria evade mammalian sabotage in the battle for iron. Nat Chem Biol. 2006;2:132-8.

85. Crouch ML, Castor M, Karlinsey JE, Kalhorn T, Fang FC. Biosynthesis and IroC-dependent export of the siderophore salmochelin are essential for virulence of Salmonella enterica serovar Typhimurium. Mol Microbiol. 2008;67:971-83.

86. Caza M, Lepine F, Milot S, Dozois CM. Specific roles of the iroBCDEN genes in virulence of an avian pathogenic Escherichia coli $\mathrm{O} 78$ strain and in production of salmochelins. Infect Immun. 2008;76:3539-49.

87. Lawlor MS, O'Connor C, Miller VL. Yersiniabactin is a virulence factor for Klebsiella pneumoniae during pulmonary infection. Infect Immun. 2007;75:1463-72.

88. Bachman MA, Miller VL, Weiser JN. Mucosal lipocalin 2 has pro-inflammatory and iron-sequestering effects in response to bacterial enterobactin. PLoS Pathog. 2009;5:e1000622.

89. Schubert S, Rakin A, Karch H, Carniel E, Heesemann J. Prevalence of the "high-pathogenicity island" of Yersinia species among Escherichia coli strains that are pathogenic to humans. Infect Immun. 1998;66:480-5.

90. Nelson AL, Barasch JM, Bunte RM, Weiser JN. Bacterial colonization of nasal mucosa induces expression of siderocalin, an iron-sequestering component of innate immunity. Cell Microbiol. 2005;7:1404-17.

91. Hornsby MJ, Huff JL, Kays RJ, Canfield DR, Bevins CL, Solnick JV. Helicobacter pylori induces an antimicrobial response in rhesus macaques in a cag pathogenicity island-dependent manner. Gastroenterology. 2008;134:1049-57.

92. Conti HR, Shen F, Nayyar N, Stocum E, Sun JN, Lindemann MJ, et al. Th17 cells and IL-17 receptor signaling are essential for mucosal 
host defense against oral candidiasis. J Exp Med. 2009;206:299311.

93. Corbin BD, Seeley EH, Raab A, Feldmann J, Miller MR, Torres $\mathrm{VJ}$, et al. Metal chelation and inhibition of bacterial growth in tissue abscesses. Science. 2008;319:962-5.

94. Liang SC, Tan XY, Luxenberg DP, Karim R, Dunussi-Joannopoulos $\mathrm{K}$, Collins M, et al. Interleukin (IL)-22 and IL-17 are coexpressed by Th17 cells and cooperatively enhance expression of antimicrobial peptides. J Exp Med. 2006;203:2271-9.

95. Happel KI, Zheng M, Young E, Quinton LJ, Lockhart E, Ramsay AJ, et al. Cutting edge: roles of Toll-like receptor 4 and IL-23 in
IL-17 expression in response to Klebsiella pneumoniae infection. J Immunol. 2003;170:4432-6.

96. Aujla SJ, Dubin PJ, Kolls JK. Th17 cells and mucosal host defense. Semin Immunol. 2007;19:377-82.

97. Brenchley JM, Price DA, Schacker TW, Asher TE, Silvestri G, Rao $\mathrm{S}$, et al. Microbial translocation is a cause of systemic immune activation in chronic HIV infection. Nat Med. 2006;12:1365-71.

98. Gordon MA, Banda HT, Gondwe M, Gordon SB, Boeree MJ, Walsh AL, et al. Non-typhoidal salmonella bacteraemia among HIV-infected Malawian adults: high mortality and frequent recrudescence. Aids. 2002;16:1633-41. 